\title{
Effect of black tea and black tea pomace polyphenols on $\alpha$-glucosidase and $\alpha$-amylase inhibition, relevant to type 2 diabetes prevention
}

\author{
Lisa Striegel ${ }^{1,2}$, Bouhee Kang ${ }^{1}$, Sarah J. Pilkenton ${ }^{1}$, Michael Rychlik ${ }^{2}$ and Emmanouil Apostolidis ${ }^{1}$ * \\ ${ }^{1}$ Department of Chemistry and Food Science, Framingham State University, Framingham, MA, USA \\ ${ }^{2}$ Technische Universitaet Muenchen, Chair of Analytical Food Chemistry, Freising, Germany
}

Edited by:

Marcello Iriti, Milan State University, Italy

Reviewed by:

Vesna Rastija, University of Osijek, Croatia

Muhammad Safder, University of Karachi, Pakistan

${ }^{*}$ Correspondence:

Emmanouil Apostolidis, Department of Chemistry and Food Science,

Framingham State University, 100

State Street, Framingham, MA 01701, USA

e-mail: eapostolidis@framingham.edu
This study evaluates the potential mechanism of action and bioactivity of black tea and black tea pomace for type 2 diabetes prevention via inhibition of carbohydrate hydrolyzing enzymes. Black tea leaves were extracted in hot water and black tea pomace was extracted in 70\% acetone. The phenolic content of the water extract (WBT) and pomace acetone extracts (AOBT) were 5.77 and $8.9 \mathrm{mg} / \mathrm{mL}$, respectively, both based on the same concentration of solid tea in the extract. The water extract was subjected to $\mathrm{C}_{18}$ extraction and the resulting hydrophobic fraction (HBBT) was further subjected to LH-20 extraction to recover a low molecular weight phenolic enriched fraction (LMW) and a high molecular weight enriched fraction (HMW). The phenolic content of the LMW and HMW fraction were 1.42 and $2.66 \mathrm{mg} / \mathrm{mL}$, respectively. Among water extracts the HMW fraction was most bioactive against $\alpha$-glucosidase $\left(I C_{50}=8.97 \mu \mathrm{g} / \mathrm{mL}\right)$ followed by HBBT fraction $\left(I C_{50}=14.83 \mu \mathrm{g} / \mathrm{mL}\right)$. However, the HBBT fraction was the most bioactive fraction against $\alpha$-amylase $\left(I C_{50}=0.049 \mathrm{mg} / \mathrm{mL}\right.$ ). The black tea pomace (AOBT) had significant $\alpha$ glucosidase inhibitory activity $\left(I C_{50}=14.72 \mu \mathrm{g} / \mathrm{mL}\right)$ but lower $\alpha$-amylase inhibitory activity $\left(I C_{50}=0.21 \mathrm{mg} / \mathrm{mL}\right)$. The phenolic profiles for LMW and HMW fractions were evaluated using HPLC and the differences between the two profiles were identified. Further research is underway to identify and evaluate the phenolic compounds that are present in the HMW fraction. Our findings suggest that black tea and black tea pomace has potential for carbohydrate hydrolyzing enzyme inhibition and this activity depends on high molecular weight phenolic compounds.

Keywords: $\alpha$-glucosidase inhibition, black tea, black tea pomace, $\alpha$-amylase inhibition, phenolic compounds, type 2 diabetes, pre-diabetes

\section{INTRODUCTION}

According to International Diabetes Federation (IDF) worldwide 382 million people in 2013 had diabetes and this number is projected to increase to 592 million by 2035 (1). This dramatic increase is mainly due to the increasing incidence of type 2 diabetes (1), also called non-insulin-dependent diabetes, which is caused by the body's ineffective use of insulin (2). To prevent the increase of type 2 diabetes, Centers of Disease Control and Prevention (CDC) defined a state of borderline type 2 diabetic patients, as pre-diabetes. The American Diabetes Association defines pre-diabetic individual as an individual with blood glucose levels higher than normal (impaired fasting glucose between 100 and $125 \mathrm{mg} / \mathrm{dL}$, impaired glucose tolerance between 140 and $199 \mathrm{mg} / \mathrm{dL}$, and HbAlc between 5.7 and $6.4 \%$ ) but not high enough to be considered

Abbreviations: AOBT, acetone extract black tea; HBBT, hydrophobic fraction from black tea water extract; HMW, high molecular phenolic-containing fraction (resulting from HBBT); HPBT, hydrophilic fraction from black tea water extract; LMW, low molecular weight phenolic-containing fraction (resulting from HBBT); WBT, water extract black tea. diabetic (impaired fasting glucose between $>126 \mathrm{mg} / \mathrm{dL}$, impaired glucose tolerance between $>200 \mathrm{mg} / \mathrm{dL}$, and HbAlc between $>6.5 \%)(3,4)$.

Beside lifestyle change, which can prevent type 2 diabetes there are also food-based active ingredients, such as polyphenols, which have the ability to modulate blood glucose level (5). Recent research has shown that phenolic compounds have the potential to inhibit carbohydrate hydrolyzing enzymes in our digestive organs and thus have potential to play a role in management of type 2 diabetes (6).

The major source of glucose in our body comes from the hydrolysis of dietary carbohydrates, such as starch. The pancreatic alpha-amylase and intestinal alpha-glucosidases are the hydrolyzing enzymes responsible for glucose generation via diet (6). $\alpha$-Amylase hydrolyzes alpha-1,4-glycocidic bonds and splits up starch components such as amylose and amylopectin into smaller oligosaccharides and disaccharides, like maltose. The $\alpha$ glucosidases hydrolyze disaccharides to monosaccharides. Previous reports suggest that the inhibition of these enzymes can be an important concept for management of type 2 diabetes $(7,8)$. Additional studies have shown that $\alpha$-glucosidase inhibitors, such 
as acarbose, are the only oral anti-diabetes agent approved for the treatment of pre-diabetes (9).

Tea is one of the most consumed beverages of the world. The tea plant (Camellia sinensis) from which the beverage tea is processed is a member of the genus Camellia and has over 200 species and is originated in the highlands of Tibet, north eastern India, and southern China. Today the major tea production countries are India, China, Sri Lanka, Kenya, Japan, Vietnam, Bangladesh, and Indonesia (10). Tea is generally consumed as green tea, oolong tea, or black tea (11). This classification is according to degree of fermentation: unfermented tea is green tea, semi-fermented tea is oolong tea, and fully fermented tea is black tea (10). The different process leads to unique characteristics, taste, and chemical profile. Of these three types, black tea is most widely produced and consumed, approximately $80 \%$.

Polyphenols belong to phenolic phytochemicals and are secondary plant metabolites, widely distributed in plants. They are known to be strong antioxidants and hence they are able to prevent tissue damage caused by free radicals (10). The major phenolic compounds present in green tea are flavonols, and more specifically catechins (10). Compared to green tea, the catechin content in black tea is reduced by approximately $85 \%$ and transformed into teaflavin-3-3'-digallate and thearubigin, which are catechin polymerization products (10). Previous research suggests that these compounds can retard the absorption of glucose by inhibition of carbohydrate hydrolyzing enzymes, such as $\alpha$-glucosidase and $\alpha$ amylase in the digestive organs. Hence, $\alpha$-glucosidase inhibitors can retard the liberation of glucose from dietary complex carbohydrates and delay glucose absorption, resulting in reduced postprandial plasma glucose levels and suppression of postprandial hyperglycemia. This could be a good treatment for type 2 diabetes prevention (12). Specifically for tea, Kwon et al. (6) reported that green tea had the lowest $\alpha$-glucosidase inhibitory activity, followed by Oolong tea and black tea had the highest inhibitory activity. These findings suggest that the observed $\alpha$-glucosidase inhibitory activity possibly depends on the catechin polymerization products that are produced during fermentation.

In this study, we evaluate the potential mechanism and bioactives of black tea and black tea pomace for type 2 diabetes prevention via inhibition of carbohydrate hydrolyzing enzymes. More specifically, we focus on the evaluation of black tea water extract polyphenols and investigate if the observed bioactivity is low molecular weight phenolic dependent (i.e., catechins) or high molecular weight phenolic dependent (i.e., catechin polymerization products). Additionally, we extract the resulting pomace using acetone and briefly evaluate its potential for carbohydrate hydrolyzing enzyme inhibition. Completion of this study gives a better understanding of the possible effect and mechanism of black tea and black tea pomace for possible prevention of type 2 diabetes.

\section{MATERIALS AND METHODS CHEMICAL/MATERIALS USED}

The black tea used in our experiment (Lipton - Earl Grey bergamot flavor) was purchased from a local supermarket (Stop and Shop, Framingham, MA, USA). $\alpha$-Glucosidase from Saccharomyces cerevisiae (EC 3.2.1.20) as well as porcine pancreatic $\alpha$-amylase (EC 3.2.1.1) were purchased from Sigma-Aldrich Co. (St. Louis, MO,
USA). Unless noted, all chemicals were also purchased from Sigma-Aldrich Co. (St. Louis, MO, USA). All solvents used were HPLC grade.

\section{SAMPLE PREPARATION}

Initially, $7.5 \mathrm{~g}$ tea leaves were extracted in $75 \mathrm{ml}$ of distilled water for $30 \mathrm{~min}$ at $90^{\circ} \mathrm{C}$. After extraction the resulting sample was filtered through a Whatman \#54 to give the initial working sample (WBT). WBT was stored at $4^{\circ} \mathrm{C}$ until further testing. The resulting pomace was collected from the filter and was extracted in $70 \%$ acetone. Briefly, leaves were dried in a drying oven at $100^{\circ} \mathrm{C}$ (AOBT). After drying, $6 \mathrm{~g}$ of the dried leaves were extracted in $60 \mathrm{~mL}$ of a $70 \%$ acetone solution for $2 \mathrm{~h}$ at room temperature and under constant stirring. The resulting extract was filtered using a Whatman \#54 filter and stored at $4^{\circ} \mathrm{C}$ until further testing.

\section{C $_{18}$ CARTRIDGe EXTRACTION}

The water extract ( $20 \mathrm{~mL}$ of WBT) was subjected to solid phase extraction using $\mathrm{C}_{18}$ cartridge (DSC-18, $3 \mathrm{~mL}$ Tube, $500 \mathrm{mg}$; Supelco, Bellefonte, PA, USA). A subsample $(500 \mu \mathrm{L})$ of the extract was loaded onto each pre-conditioned $\mathrm{C}_{18}$ (acetone followed by distilled water) followed by rinsing with deionized water to remove the hydrophilic compounds (HPBT). After washing, the hydrophobic compounds (including phenolic compounds) were eluted with $5 \mathrm{~mL}$ of 99:1 (v/v) methanol:acetic acid solution (HBBT). The solvent and water were evaporated from HBBT and HPBT, respectively, using a rotary evaporator (Fisher Scientific; Hanover Park, IL, USA) at $60^{\circ} \mathrm{C}$ to yield a final volume of $20 \mathrm{~mL}$. The evaporated extract was stored at $-4^{\circ} \mathrm{C}$ until further testing.

\section{LH-20 COLUMN EXTRACTION}

The hydrophobic fraction (HBBT) was subjected to gel filtration chromatography using Sephadex LH-20 column extraction to recover a high molecular weight fraction (HMW) and a low molecular weight fraction (LMW) of phenolic compounds. Three milliliter of hydrophobic fraction was loaded onto $40 \mathrm{~mL} \mathrm{LH}-20$ column, which has been conditioned by washing with $200 \mathrm{~mL}$ of $30 \%$ methanol. The column was washed with $600 \mathrm{~mL} 30 \%$ methanol to recover low molecular weight phenolic compounds (LMW) and with $100 \mathrm{~mL}$ of acetone: deionized water: acetic acid (70:29.9:0.01) (v/v/v) to collect the high molecular weight phenolic compounds (HMW). A total of $20 \mathrm{~mL}$ of HBBT was subjected to LH-20 extraction in portions of 2 and $3 \mathrm{~mL}$ and finally both fractions were roto-evaporated by vacuum rotor evaporator (Fisher Scientific; Hanover Park, IL, USA) to $20 \mathrm{~mL}$ to remove solvents and stored at $4^{\circ} \mathrm{C}$ until further testing.

\section{TOTAL PHENOLIC CONTENT DETERMINATION}

The phenolic content of all extracts was determined by an assay modified from Shetty et al. (13). Briefly, $0.5 \mathrm{~mL}$ of sample or standard was mixed with $0.5 \mathrm{~mL}$ distilled water, $1 \mathrm{~mL} \mathrm{95 \%} \mathrm{ethanol,}$ $5 \mathrm{~mL}$ distilled water, and $0.5 \mathrm{~mL} \mathrm{50 \%} \mathrm{(v/v)} \mathrm{Folin-Ciocalteu} \mathrm{reagent}$ in test tubes. Then the test tubes were incubated at room temperature for $5 \mathrm{~min}$. After adding of $1 \mathrm{~mL}$ of $5 \% \mathrm{Na}_{2} \mathrm{CO}_{3}$, the mixtures were kept in the dark at room temperature for $60 \mathrm{~min}$. The absorbance was measured at $725 \mathrm{~nm}$ (U 2001 Spectrophotometer; 
Hitachi, Pleasanton, CA, USA) after vortexing. Gallic acid standards were prepared $(15.625,31.25,62.5,125,250$, and $500 \mu \mathrm{g} / \mathrm{mL}$ in ethanol) and used to establish the standard curve. Results were expressed as $\mathrm{mg}$ of gallic acid equivalents per gram of sample (DW).

\section{ANTIOXIDANT ACTIVITY BY 1,1-DIPHENYL-2-PICRYLHYDRAZYL RADICAL INHIBITION ASSAY}

The antioxidant activity by 1,1-Diphenyl-2-picrylhydrazyl (DPPH) free-radical scavenging inhibition was determined following the procedure modified from Shetty et al. (13). The percentage antioxidant activity (AA\%) was determined in a dosedependent manner. Stock DPPH solution was prepared by adding $39 \mathrm{mg}$ DPPH in $100 \mathrm{~mL} \mathrm{95 \%} \mathrm{ethanol.} \mathrm{To} 1 \mathrm{~mL}$ of DPPH solution $200 \mu \mathrm{L}$ of each extract was added and the decrease in absorbance was monitored at $517 \mathrm{~nm}$, using a spectrophotometer (U 2001 Spectrophotometer; Hitachi, Pleasanton, CA, USA) until a constant reading was obtained. The readings were compared with the controls, which contained $200 \mu \mathrm{L}$ of water instead of the extract. The $\%$ inhibition was calculated by:

$$
\% \text { inhibition }=\left(\frac{\mathrm{Abs}_{\mathrm{control}}-\mathrm{Abs}_{\text {sample }}}{\mathrm{Abs}_{\mathrm{control}}}\right) \times 100
$$

\section{YEAST- $\alpha$-GLUCOSIDASE INHIBITION ASSAY}

The dose-dependent yeast $\alpha$-glucosidase inhibitory activity was determined in all whole extracts and recovered hydrophilic and hydrophobic fractions after $\mathrm{C}_{18}$ extraction. A mixture of $50 \mu \mathrm{L}$ extract and $100 \mu \mathrm{L}$ of $0.1 \mathrm{M}$ phosphate buffer ( $\mathrm{pH}$ 6.9) containing $\alpha$-glucosidase solution $(1.0 \mathrm{U} / \mathrm{mL})$ were incubated in 96 well plates at $25^{\circ} \mathrm{C}$ for $10 \mathrm{~min}$. After pre-incubation, $50 \mu \mathrm{L}$ of $5 \mathrm{mM}$ p-nitrophenyl- $\alpha$-D-glucopyranoside solution in $0.1 \mathrm{M}$ phosphate buffer ( $\mathrm{pH}$ 6.9) was added to each well at timed intervals. The reaction mixtures were incubated at $25^{\circ} \mathrm{C}$ for $5 \mathrm{~min}$. Before and after incubation, absorbance was recorded at $405 \mathrm{~nm}$ by microplate reader (VMax, Molecular Device Co., Sunnyvale, CA, USA) and compared to that of the control, which had $50 \mu \mathrm{L}$ buffer solution in place of the extract. The $\alpha$-glucosidase inhibitory activity was expressed as inhibition $\%$ and was calculated as followed:

$$
\% \text { inhibition }=\left(\frac{\Delta \mathrm{Abs}_{\text {control }}-\Delta \mathrm{Abs}_{\text {sample }}}{\Delta \mathrm{Abs}_{\text {control }}}\right) \times 100
$$

\section{PORCINE $\alpha$-AMYLASE INHIBITION ASSAY}

The dose-dependent $\alpha$-amylase inhibitory activity of water extracts was evaluated. A mixture of $500 \mu \mathrm{L}$ extract and $500 \mu \mathrm{L}$ $0.02 \mathrm{M}$ sodium phosphate buffer $(\mathrm{pH} 6.9$ with $0.006 \mathrm{M}$ sodium chloride) containing $\alpha$-amylase solution $(13 \mathrm{U} / \mathrm{mL})$ was incubated at $25^{\circ} \mathrm{C}$ for $10 \mathrm{~min}$. After pre-incubation, $500 \mu \mathrm{L}$ of $1 \%$ soluble starch solution in $0.02 \mathrm{M}$ sodium phosphate buffer $(\mathrm{pH} 6.9$ with $0.006 \mathrm{M} \mathrm{NaCl}$ ) was added to each tube at timed intervals. The reaction mixtures were then incubated at $25^{\circ} \mathrm{C}$ for $10 \mathrm{~min}$ followed by addition of $1 \mathrm{~mL}$ dinitrosalicylic acid color reagent (14). The test tubes were then placed in a boiling water bath for 5 min to stop the reaction and cooled to room temperature. The reaction mixture was then diluted with $10 \mathrm{~mL}$ of distilled water and the absorbance was read at $540 \mathrm{~nm}$. The \% inhibitory activity was determined using the following equation:

$$
\% \text { inhibition }=\left(\frac{\Delta \mathrm{Abs}_{\text {control }}-\Delta \mathrm{Abs}_{\text {sample }}}{\Delta \mathrm{Abs}_{\text {control }}}\right) \times 100
$$

\section{PHENOLIC PROFILE DETERMINATION WITH HPLC}

The obtained HBBT, HMW, and LMW fractions were subjected to HPLC to identify the differences in their phenolic profile. All tested samples were concentrated by rotary evaporation (Fisher Scientific; Hanover Park, IL, USA) to complete dryness and were re-dissolved in $1 \mathrm{~mL}$ of acetone. To $800 \mu \mathrm{L}$ of each sample we added $400 \mu \mathrm{L}$ of distilled water and the resulting solutions were filtered using a $0.45 \mu \mathrm{m}$ Fisherbrand ${ }^{\circledR}$ syringe filter (Thermo Fisher Sci, Pittsburg, PA, USA). An injection volume of $20 \mu \mathrm{L}$ of each sample was injected and analyzed using a reverse phase C-18 column (Agilent ZORBAX Extend C-18 column, $250 \times 4.6 \mathrm{~mm}$ id.d, $5 \mu \mathrm{m}$ particle size). The mobile phase consisted of solvent A ( $4 \%$ phosphoric acid) and solvent B (acetonitrile). Gradient elution was used under linear gradient conditions starting with $95 \% \mathrm{~A}$ and decreasing linearly to $65 \% \mathrm{~A}$ over a 70 minute time period at a flow rate of $0.75 \mathrm{~mL} / \mathrm{min}$. Phenolic profiles were observed at $254 \mathrm{~nm}$ and $280 \mathrm{~nm}$ using a UV-VIS detector.

\section{STATISTICAL ANALYSIS}

All experiments were performed at least three times in triplicates. Analysis at every time point from each experiment was carried out in triplicates. Means, standard errors, standard deviations, and $\mathrm{IC}_{50}$ values were calculated using Microsoft Excel XP.

\section{RESULTS}

\section{TOTAL PHENOLIC CONTENT}

The total phenolic content analyzed by Folin-Ciocalteau's method indicated that WBT had a phenolic content of $5.77 \mathrm{mg} / \mathrm{mL}$ (Figure 1). As expected the total phenolic content of HBBT

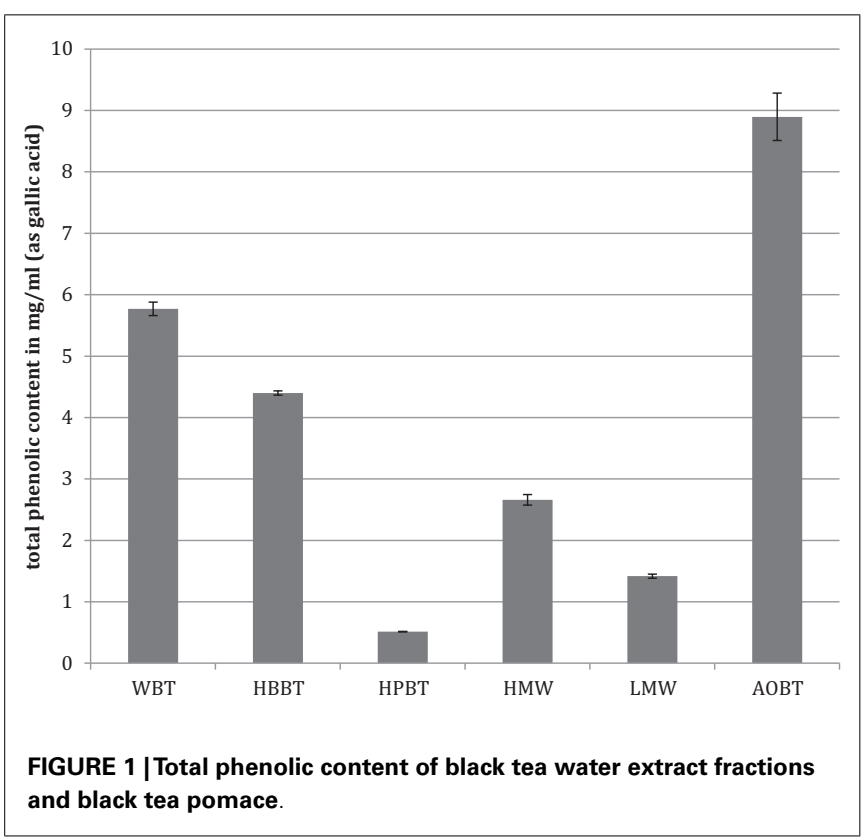


was higher than the total phenolic content of HPBT (4.4 and $0.52 \mathrm{mg} / \mathrm{mL}$, respectively) (Figure 1). After LH-20 extraction of HBBT fraction the total phenolic content of HMW and LMW were determined to be 2.66 and $1.43 \mathrm{mg} / \mathrm{mL}$, respectively (Figure 1).

The WBT fraction had the highest phenolic content followed by the HBBT fraction, which resulted after the $\mathrm{C}_{18}$ extraction. The HBBT fraction was further subjected to LH-20 column separation resulting in HMW and LMW fraction. HMW fraction had higher phenolic content and the sum of both HMW and LMW phenolic contents was similar to the HBBT phenolic content, suggesting a successful recovery of phenolic phytochemicals following LH20 extraction. This shows that all phenolic compounds initially present in the HBBT fraction were eluted either in methanol or in acetone.

The phenolic content of pomace acetone extract (AOBT) was $8.63 \mathrm{mg} / \mathrm{mL}$ (Figure 1), suggesting that black tea pomace resulting from hot water black tea extraction contains significant amount of phenolic compounds that cannot be extracted using water as an extraction medium.

\section{ANTIOXIDANT ACTIVITY BY DPPH RADICAL INHIBITION ASSAY}

The antioxidant activity in terms of DPPH free-radical scavenging potential was evaluated for WBT, HBBT, and HPBT (Figure 2). All tested samples had antioxidant activity in a dose-dependent manner in the tested doses. More specifically, WBT fraction had the highest antioxidant activity with $95.4 \%$ radical inhibition ( $50 \times$ dilution) followed by HBBT $(86.2 \%$ at the same dilution) (Figure 2). HPBT fractions had the lowest antioxidant activity

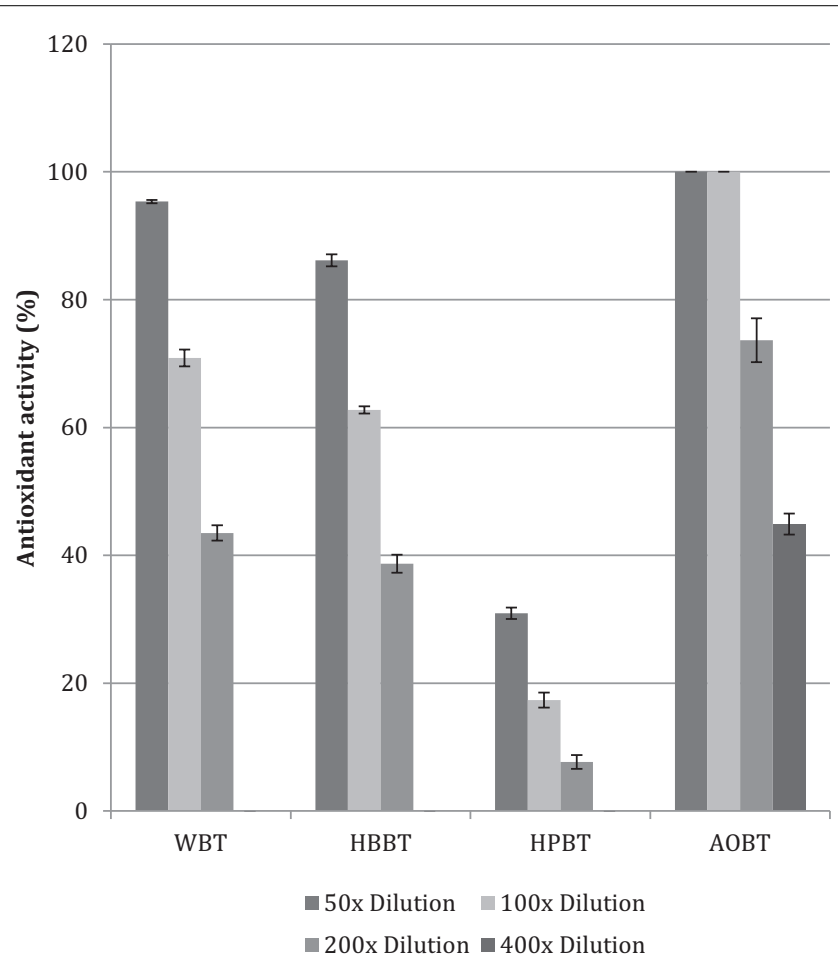

FIGURE 2 | Antioxidant activity of black tea water extract fractions and black tea pomace.
(30.9\% at the same dilution) (Figure 2). When the black tea pomace acetone extract (AOBT) was evaluated we determined that it had the highest antioxidant activity $(100 \%$ at $50 \times$ dilution $)$ (Figure 2).

It is well documented that phenolic phytochemicals are effective antioxidants $(6,15-18)$ and our findings indicate that the antioxidant activities are in agreement with the phenolic contents (Figures 1 and 2).

\section{$\alpha$-GLUCOSIDASE INHIBITION ASSAY}

The dose-dependent $\alpha$-glucosidase inhibitory activities of WBT, HBBT, HPBT, LMW, HMW, and AOBT were investigated. For comparison, the results were expressed in $\mathrm{IC}_{50}$ values based on the phenolic content (the phenolic concentration of extracts resulting in $50 \%$ inhibition of enzyme activity). We observed that the HMW fraction appeared to be the most bioactive fraction $\left(\mathrm{IC}_{50} 8.97 \mu \mathrm{g}\right.$ phenolics $/ \mathrm{mL}$ ), followed by the HBBT fraction, with an $\mathrm{IC}_{50}$ of $14.8 \mu \mathrm{g}$ phenolics/mL (Table 1). The $\mathrm{IC}_{50}$ of the WBT and LMW fractions were calculated to be 22.4 and $34.2 \mu \mathrm{g}$ phenolics $/ \mathrm{mL}$, respectively, followed by HPBT $\left(\mathrm{IC}_{50}: 503 \mu \mathrm{g} / \mathrm{mL}\right.$ ), which had the lowest inhibitory activity (Table $\mathbf{1})$.

Our observations clearly suggest that the most bioactive components in black tea for $\alpha$-glucosidase inhibition are high molecular weight phenolic compounds. Our observations are in agreement with our preliminary observations that the $\alpha$-glucosidase inhibitory activity increases as tea is fermented (6). During fermentation low molecular weight catechins are polymerized to form higher molecular weight teaflavin-3-3'-digallate and thearubigin, which are catechin polymerization products (10).

When the $\alpha$-glucosidase inhibitory activity of AOBT was evaluated we observed an $\mathrm{IC}_{50} 14.7 \mu \mathrm{g}$ phenolics/mL (Table 1). This inhibitory activity is lower than HBBT and HMW than the whole black tea water extract (WBT). Our findings suggest that the black tea pomace contains hydrophobic compounds that are not extracted during hot water extraction, which have significant potential for type 2 diabetes prevention via inhibition of carbohydrate hydrolyzing enzymes. We suspect that these compounds are hydrophobic in nature and most probably higher molecular weight catechin polymerization products.

\section{$\alpha$-AMYLASE INHIBITION ASSAY}

Similarly to the $\alpha$-glucosidase inhibitory activities, the $\mathrm{IC}_{50}$ values of the $\alpha$-amylase inhibitory activities were estimated for all samples (Table 2). The $\mathrm{IC}_{50}$ of the WBT fraction was $1.74 \mathrm{mg}$ phenolics/mL, while the inhibitory activity of the HBBT fraction was the most bioactive of all the tested fractions with an $\mathrm{IC}_{50}$ of $0.049 \mathrm{mg}$ phenolics $/ \mathrm{mL}$. The HPBT fraction had a negligible $\mathrm{IC}_{50}$ (131 mg phenolics $/ \mathrm{mL}$ ), while the $\mathrm{IC}_{50}$ of the HMW fraction was calculated to be $0.42 \mathrm{mg}$ phenolics $/ \mathrm{mL}$. Finally, AOBT extract resulted to an $\mathrm{IC}_{50}$ value of $0.21 \mathrm{mg}$ phenolics $/ \mathrm{mL}$.

Table 1 | Yeast $\alpha$-glucosidase inhibition IC $_{50}$ values based on total phenolic content.

\begin{tabular}{lcccccc}
\hline & WBT & HBBT & HPBT & LMW & HMW & AOBT \\
\hline $\mathrm{IC}_{50}(\mu \mathrm{g} / \mathrm{mL})$ & 22.4 & 14.8 & 502 & 34.2 & 8.97 & 14.7
\end{tabular}


Table 2 | $\alpha$-Amylase inhibition IC $_{50}$ values based on total phenolic content

\begin{tabular}{lcccccc}
\hline & WBT & HBBT & HPBT & LMW & HMW & AOBT \\
\hline $\mathrm{IC}_{50}(\mathrm{mg} / \mathrm{mL})$ & 1.74 & 0.049 & 131 & - & 0.42 & 0.21
\end{tabular}

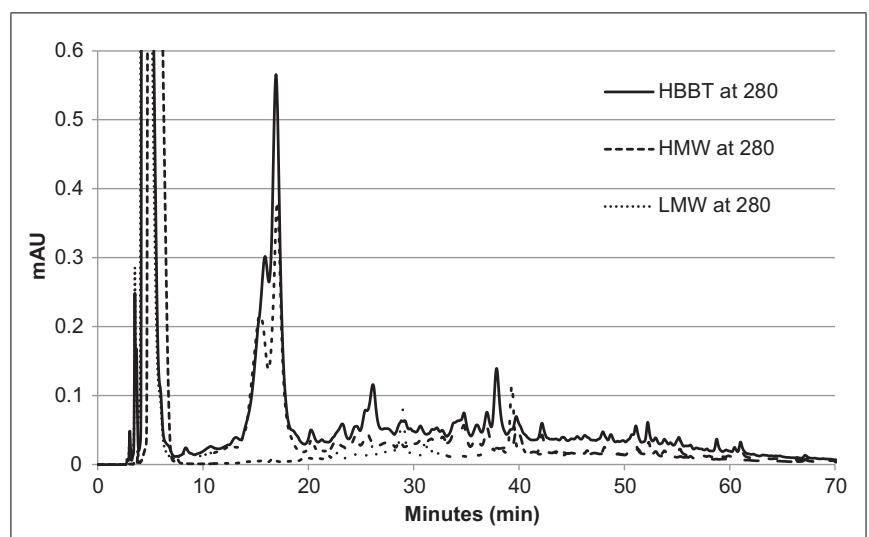

FIGURE 3 | HPLC chromatogram of HBBT, HMW, and LMW at $280 \mathrm{~nm}$.

After comparing the resulting $\alpha$-glucosidase and $\alpha$-amylase $\mathrm{IC}_{50}$ values the $\alpha$-amylase inhibitory activity of the testes samples was lower than the $\alpha$-glucosidase inhibitory activity (Tables 1 and 2). The main side effects of type 2 diabetes control drugs, such as acarbose, are abdominal distention, flatulence, meteorism, and possibly diarrhea (19). It has been suggested that such adverse effects might be caused by the excessive inhibition of pancreatic $\alpha$-amylase resulting in the abnormal bacterial fermentation of undigested carbohydrates in the colon (19). In our study, although we observed a low $\alpha$-amylase inhibitory activity, the possibility of reduced side effects linked to excessive inhibition of starch digestion is suggested.

\section{PHENOLIC PROFILE DETERMINATION WITH HPLC}

To confirm the successful fractionation using LH-20 extraction, the phenolic profiles of HBBT, LMW, and HMW were determined at 254 and $280 \mathrm{~nm}$ as described in the Section "Materials and Methods" (Figures 3 and 4). Our observations suggest a different phenolic profile in the three tested samples. The HBBT and LMW fraction showed two peaks after 15.6 and $16.7 \mathrm{~min}$ with $\lambda_{\max }$ at $280 \mathrm{~nm}$ (Figure 3). These peaks were absent in the HMW fraction. Additionally, at 34.7, 35.8, and $36.8 \mathrm{~min}$ the HBBT and LMW fractions showed peaks with $\lambda_{\max }$ at $254 \mathrm{~nm}$ (Figure 4). There were also peaks at 39.7 and $42.1 \mathrm{~min}$ with a $\lambda_{\max }$ at $254 \mathrm{~nm}$ found in the HBBT and LMW fractions (Figure 4). These findings suggest that these peaks are possibly low molecular weight phenolic compounds. We were also able to identify unique peaks found only in the HBBT and HMW fraction. We noticed that the HMW chromatogram was slightly shifted, when compared to the HBBT. In the HBBT fraction, two peaks were identified at 25.0 and $25.8 \mathrm{~min}$. The same peaks could be identified in the HMW fraction after 28.6 and $28.9 \mathrm{~min}$. Additionally, in HBBT a peak was identified at $37.7 \mathrm{~min}$ and this peak was also detected in the HMW

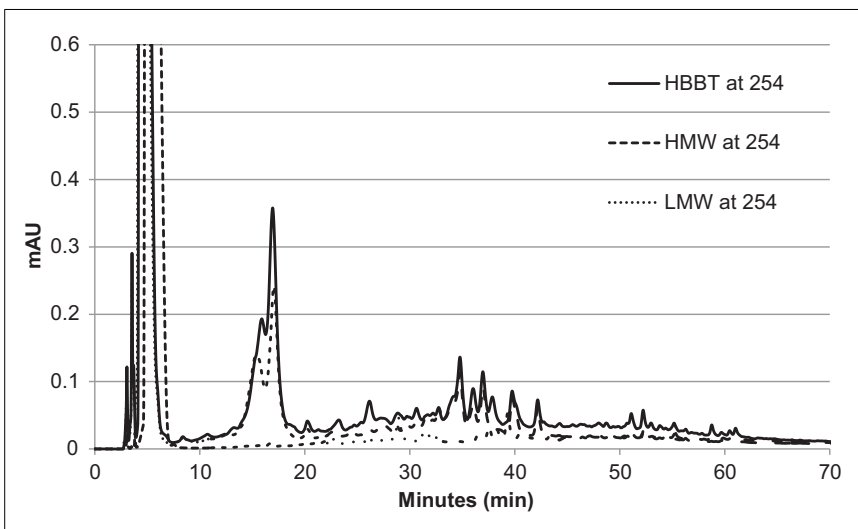

FIGURE 4 | HPLC chromatogram of HBBT, HMW, and LMW at $254 \mathrm{~nm}$.

fraction at $39.2 \mathrm{~min}$. Both peaks had a $\lambda_{\max }$ at $280 \mathrm{~nm}$ (Figure 3 ). Furthermore, three more peaks were identified to be unique for the HBBT and HMW fraction. These compounds eluted at 47.4, 58.7, and $70.0 \mathrm{~min}$ and had a $\lambda_{\max }$ at $280 \mathrm{~nm}$ (Figure 3 ) and could not be identified in the LMW fraction.

Our results suggest that LH-20 extraction of HBBT using two different solvents yielded two different fractions (LMW and HMW) that have different phenolic profile. Although no compounds were characterized in this research, we suspect that the peaks appearing in both HBBT and HMW are high molecular weight catechin polymerization products. More research is underway to effectively characterize the resulting HMW fraction and link the identified compounds with specific carbohydrate hydrolyzing enzyme inhibitory activity.

\section{CONCLUSION}

Type 2 diabetes is an emerging health concern in many parts of the world. It is projected that diabetes will increase dramatically during the next years and will be the 7th leading cause of death in 2030 , mainly due to the increase in the incidence of type 2 diabetes $(1,2)$.

It is well documented that phenolic phytochemicals have $\alpha$ glucosidase inhibitory activity that depends on the phenolic profile $(6,17,20)$. A recent study reported that cinnamon extract has $\alpha$-glucosidase inhibitory activity, which is low molecular weight phenolic dependent (20). Another study in our lab showed that the $\alpha$-glucosidase inhibitory activity of blueberries is low molecular weight phenolic dependent (21). In the case of blueberries and cinnamon, the predominant high molecular weight phenolic compounds are proanthocyanidins.

In this preliminary work, we identified that both black tea water extract and black tea pomace have potential for type 2 diabetes prevention, via inhibition of carbohydrate hydrolyzing enzymes, namely $\alpha$-glucosidase. The same extracts have a low $\alpha$-amylase inhibitory activity. Strong inhibition of $\alpha$-glucosidase and low inhibition of $\alpha$-amylase could be potentially used as an effective complementary therapy for postprandial hyperglycemia linked to type 2 diabetes with reduced side effects. Our fractionation results, coupled with the high bioactivity of the black tea pomace, suggest that the observed effects are probably due to high molecular weight 
phenolics present in black tea, namely catechin polymerization products. This conclusion is further supported from our previous findings (6) that suggest that $\alpha$-glucosidase inhibition in tea increases during fermentation. Further investigation is underway to identify the specific high molecular weight phenolic compounds in black tea and pomace of water extraction that are relevant to the inhibition of carbohydrate hydrolysis enzymes.

\section{AUTHOR CONTRIBUTIONS}

LS, BK, and SP carried out tea extraction, fractionization, and the inhibition assays. The study was designed by EA. The manuscript was written by LS, MR, and EA.

\section{REFERENCES}

1. IDF (International Diabetes Federation). (2014). Available from: http://www. idf.org/worlddiabetesday/toolkit/gp/facts-figures

2. WHO (World Health Organization). (2014). Available from: http://www.who. int/mediacentre/factsheets/fs312/en/

3. American Diabetes Association. Diagnosis and classification of diabetes mellitus. Diabetes Care (2013) 36:67-74. doi:10.2337/dc13-S067

4. Tabak AG, Herder C, Rathmann W, Brunner EJ, Kivimaki M. Prediabetes: a high-risk state for diabetes development. Lancet (2012) 379:2279-90. doi:10. 1016/S0140-6736(12)60283-9

5. Thondre PS. Food-based ingredients to modulate blood glucose. Adv Food Nutr Res (2013) 70:181-227. doi:10.1016/B978-0-12-416555-7.00005-9

6. Kwon Y-I, Apostolidis E, Shetty K. Inhibitory potential of wine and tea against alpha-amylase and alpha-glucosidase for management of hyperglycemia linked to type 2 diabetes. J Food Biochem (2008) 32:15-31. doi:10.1002/bab.1105

7. Apostolidis E, Lee CM. In vitro potential of Ascophyllum nodosum phenolic antioxidant- mediated alpha- glucosidase and alpha- amylase. J Food Sci (2010) 75:H97-102. doi:10.1111/j.1750-3841.2010.01544.x

8. Friedmann M, Kim S-Y, Lee S-J, Han G-P, Han JS, Lee K-R, et al. Distribution of catechins, theaflavins, caffeine, and theobromin in 77 teas consumed in the United States. J Food Sci (2005) 70:C550-8. doi:10.1111/j.1365-2621.2005. tb08304.x

9. Hanefeld M. Cardiovascular benefits and safety profile of acarbose therapy in prediabetes and established type 2 diabetes. Cardiovasc Diabetol (2007) 6:20-30. doi:10.1186/1475-2840-6-20

10. Preedy VR. Tea in Health and Disease Prevention. London, UK: Elsevier (2013).

11. Del Rio D, Stewart AJ, Mullen W, Burns J, Lean MEJ, Brighenti F, et al. HPLCMS anaylsis of phenolic compounds and purine alkaloids in green and black tea. J Agric Food Chem (2004) 52:2807-15. doi:10.1021/jf0354848

12. Kumar S, Narwal S, Kumar V, Prakash O. Alpha-glucosidase inhibitors from plants: a natural approach to treat diabetes. Pharmacogn Rev (2011) 5:19-29. doi:10.4103/0973-7847.79096

13. Shetty K, Curtis OF, Levin RE, Witkowsky R, Ang W. Prevention of vitrification associated with in vitro shoot culture of oregano (Origanum vulgare) by
Pseudomonas spp. J Plant Physiology (1995) 147:447-51. doi:10.1016/S01761617(11)82181-4

14. Worthington Enzyme Manual. (2014). Available from: http://worthingtonbiochem.com/AA/assay.html

15. Apostolidis E, Li L, Lee CM, Seeram NP. In vitro evaluation of phenolicenriched maple syrup extracts for inhibition of carbohydrate hydrolyzing enzymes relevant to type 2 diabetes management. J Funct Foods (2011) 3:100-6. doi:10.1016/j.jff.2011.03.003

16. Kwon Y, Apostolidis E, Shetty K. In vitro studies of eggplant (Solanum melongena) phenolics as inhibitors of key enzymes relevant to type 2 diabetes and hypertension. Bioresour Technol (2008) 99:2981-8. doi:10.1016/j.biortech.2007. 06.035

17. Apostolidis E, Li L, Kang B, Lee C, Seeram N. Seasonal influence on phenolicmediated antihyperglycemic properties of Canadian sugar and red maple leaves using in vitro assay models. Food Sci Biotechnol (2012) 21:1-8. doi:10.1007/ s10068-012-0098-x

18. Pinto M, Kwon Y-I, Apostolidis E, Lajolo FM, Genovse MI, Shetty K. Functionality of bioactive compounds in Brazilian strawberry (Fragaria X ananassa Duch.) cultivars: evaluation of hyperglycemia and hypertension potential using in vitro models. J Agric Food Chem (2008) 56:4386-92. doi:10.1021/jf0732758

19. Bischoff H, Puls W, Krause HP, Schutt H, Thomas G. Pharmacological properties of the novel glucosidase inhibitors BAY M 1099 (miglitol) and BAY O 1248. Diabetes Res Clin Pract (1985) (Suppl 1):S53.

20. Kang B-H, Racicot K, Pilkenton SJ, Apostolidis E. Evaluation of the in vitro antihyperglycemic effect of Cinnamomum cassia derived phenolic phytochemicals, via carbohydrate hydrolyzing enzyme inhibition. Plant Foods Hum Nutr (2014) 69:155-60. doi:10.1007/s11130-014-0415-z

21. Kang B, Racicot K, Pilkenton S, Apostolidis E. In vitro evaluation of blueberry powder of the management of type-2 diabetes and identification of responsible bioactive components. IFT 2014 Annual Meeting. New Orleans, LA (2014).

Conflict of Interest Statement: The authors declare that the research was conducted in the absence of any commercial or financial relationships that could be construed as a potential conflict of interest.

Received: 26 October 2014; paper pending published: 13 January 2015; accepted: 29 January 2015; published online: 12 February 2015.

Citation: Striegel L, Kang B, Pilkenton SJ, Rychlik M and Apostolidis E (2015) Effect of black tea and black tea pomace polyphenols on $\alpha$-glucosidase and $\alpha$-amylase inhibition, relevant to type 2 diabetes prevention. Front. Nutr. 2:3. doi: 10.3389/fnut.2015.00003 This article was submitted to Food Chemistry, a section of the journal Frontiers in Nutrition.

Copyright (C) 2015 Striegel, Kang, Pilkenton, Rychlik and Apostolidis. This is an openaccess article distributed under the terms of the Creative Commons Attribution License (CC BY). The use, distribution or reproduction in other forums is permitted, provided the original author(s) or licensor are credited and that the original publication in this journal is cited, in accordance with accepted academic practice. No use, distribution or reproduction is permitted which does not comply with these terms. 